\title{
II Macrothink

\section{The Linkage between Active Learning Method and Industrial Work Experience among Vocational Technology Undergraduate Students in Rivers State of Nigeria}

\begin{abstract}
Dr. S.W. Wodi
Faculty of Technical and Science Education, Department of Science and Technical Education, Rivers State University of Science and Technology Nkpolu-Oroworukwo, Port Harcourt.
\end{abstract}

Accepted: July 5, 2012 Published: August 09, 2012

Doi:10.5296/ijld.v2i4.2215 URL: http://dx.doi.org/10.5296/ijld.v2i4.2215

\begin{abstract}
In an ever-changing and increasingly competitive environment, educational institutions are continually looking at methods to improve their teaching and attract students to their courses. Students likewise are becoming more selective when choosing an institution in which to study and are more focused on the longer-term employability offered by various courses. This paper looks at this changing environment from both the industry and education perspectives, and examines one exercise, an information feedback method, which is attempting to link education closer to the world of work, by providing students with the relevant transferable skills. The empirical research conducted among the students on completion of their industrial work experience gave very positive results, with students feeling that their interpersonal skills had been greatly enhanced and that creative teaching methods such as these provided them with a competitive advantage when entering the job market. In addition to satisfying students' requirements, the research results also show that exercises of this type more fully meet the needs of the concept of deep learning', where students are given a more participatory part in their educational process. We conclude that future educational curricula should include an increasing number of activity based method by providing a better balance between the theoretical and practical elements of education and industry
\end{abstract}

Keywords: Quality Feedback, Activity method, Acquisitive skills, Creative teaching 


\section{Introduction}

In parallel with the increased attention focused on the quality of tertiary education in general Bassey and Ntukidem (2001) have been evaluating objectives, desired outcomes and appropriate forms of instructional delivery in Nigerian tertiary institutions classroom.

Teaching a subject with obvious practical applications, are constantly troubled by the need to balance the educational and vocational aspects of the curriculum. This search for balance is one echoed throughout the wider literature on university-level industrial education and is encapsulated in the notion that both theory and practice should be the goal of a university education, without sacrificing theory when incorporating practical, or experiential learning (Idialu, 1990). The benefits of an experiential, practical or activity method to learning have been widely disseminated in the report by Uyoata, (2003). Uyoata distinguished between deep and surface approaches to learning adopted by students in their survey. Surface learning, he suggest, is where students attempt to 'spot facts' in, say, a given text, particularly those they perceive as a ready focus for questions or assessment by teachers. This 'fact spotting' is followed by committing the facts to memory, focusing on the surface level of the material under study. In contrast, any attempt to understand what the author of a given text might be saying, to focus on underlying meaning and seeking to integrate the components of the text is seen as evidence of 'deep learning' by using taxonomy of cognitive components. According to Ezeife (1993), the approach adopted by students 'is not simply a characteristic of the student, but rather it is that student's reaction to a particular task or situation'. While this reaction is in part due to the student's overall purposes in studying, previous experiences of education and the conception of learning held at that time, it is also influenced by the student's perceptions of the teaching and assessment procedures encountered on the course being taken. Accordingly, it is vital to reconsider teaching and assessment on the three learning domains those forms of teaching and assessment that evoke greater levels of interest and that are likely to encourage a deep approach to learning, linking academic work to the outside world and promoting collaborative work.

This concept of 'deep learning' has been endorsed through its adoption as one of the key measurements used in 2002 benchmark by the Rivers State Government on Teaching Quality Assessment exercise in her higher institutions in Nigeria, which has been introduced as a method of judging how well tertiary education is serving the wider society. Benefits such as those mentioned above seem to dovetail neatly with the demands that industry is making of university education in general and industrial education more specifically. For instance, the seminal work of Ekpenyong, (1995) in experiential learning is of value in the quest for improving the quality of student learning. Experiential learning requires that teaching staff encourage students to reflect on their own experiences and use them in developing their understanding of a particular subject. Indeed, this approach was advocated in the work of Aikenhead (1997) in the proposition of activity based learning, described as 'a collaborative enquiry process'. The core of this enquiry process is, first, research to explore, followed by action to improve, then critical evaluation of the action which leads back into enquiry (Okebukola, 1992). 
It would seem therefore that the introduction of teaching methods which encourage active learning will not only improve the quality of understanding of the subject by students, but also provide the acquisition of working patterns and skills that employers seek in industrial technology graduates looking for opportunities in the industrial sector while, at the same time, ensuring that the tertiary education sector is fulfilling its educational, social and economic mandate.

This paper describes one of such method, namely feedback method (FBM) and reports on its success from the perspective of both the lecturers and students. The FBM is widespread in the evaluation of both learners and teachers performance.

\section{FEEDBACK METHOD EXERCISE (FMB)}

The FMB was developed by the authors of this research pooling their joint experience of industrial training they had undergone themselves as 'graduate industrial experience trainees' in factory. During the training, both had been involved in FMB used by their respective companies to introduce them to the type and pace of decisions they might typically have to face during their careers. An FMB typically presents a problem to be solved without the necessary information for the solution. Those charged with the responsibility of solving the problem must identify, locate and retrieve the information necessary to solve the problem, synthesize and interpret the information and come to a decision on the problem's solution. Thus an FMB environment provides the opportunity for research, analysis, creativity, negotiation and decision-making.

The FMB we developed is a case study, where the data required to 'solve' the problem are removed; it is stored with the instructor who runs the exercise. Although, like a case study and real-world problems, perfect and complete information is not available, the FMB requires students to emulate practical actions, in that they must first work out what information is required to solve the problem. The FMB requires that groups of students compete with one another in order to solve the problem 'better' than other groups. They must also specify the information, as they will need to do during their careers. Thus an FMB requires students to understand the nature of the problem at hand, translate it into the appropriate constituent elements about which they might find information and then they must consider where the information would be located within (or outside) the organization'. Thus the exercise tests the students' ability to think tactically as to how they will use the information. These requirements mean that students must be specific regarding the information they seek; if they ask a general or vague question, the answer is likely to mirror such qualities. The instructors were keen to assess the usefulness of the FMB and designed a small-scale research study whose objectives are described below. The objectives of the research described in the remainder of this paper were as follows:

- To understand the degree to which this type of teaching method was helping students to be better equipped for the workplace.

- To identify to what extent this method enabled students to experience the full process of learning. 
- To utilize the research results to fine-tune our students qualities

Consequently, the context for the research is set in the following issues:

- The changing attitudes to the industrial education interface;

- Academia's response to its changing environment;

- Its overall implication to the learning process

\section{THE Changing Industrial Education Curriculum and Industry Interface}

There have been many criticisms of industrial education, which has often been perceived by industry as being too theoretical in its approach, too compartmentalized due to the departmental structure operating in higher education institutions and also lacking in a holistic approach to problem-solving in academia. There are those who question the mission of the university and suggest that by solely focusing on the specifications set by industry, we are essentially betraying our own academic background and limiting the value of a true educational experience (Uyoata, 2003).

In analyzing any interface between two separate bodies, what must be taken into account is the background from which each is coming to the situation. In the industrial education/industry interface, there is a question of underlying values, which must be addressed, with industry supporting the values of enterprise and accumulation of wealth as a means of furthering development in society. Academia, on the other hand, has traditionally supported the values of academic freedom, academic rigour and the disinterested pursuit of knowledge as being of intrinsic importance to its contribution towards society's development (Ukoli, 1981).

In addition to views held by the educators and industrialists, student motivation seem also to have been subject to change in their attitudes to and demands of university education. Duruamatu (1992) conducted a study in which they found university students to be precise on their requirements of a university degree and on the type of employment they were seeking, introducing a further dimension into the industrial education/industry interface. There is therefore a need for radical changes to the curriculum in terms of both the content and delivery of courses.

\section{Academia's Response to the Changing Curriculum}

The past ten years have seen a marked increase in the amount and scope of practical/transferable skills being incorporated into the curricula on offer, particularly in industrial education. The intention is to have a system based on what employers need people to be able to do rather than on what educationalists and trainers have traditionally assumed they need to know (Bassey, 2001).

This increased recognition in education of the importance of transferable/personal skills has not solely been confined to the tertiary education sector. Many in the secondary school sector have recognized the need to introduce the concept of 'enterprise learning' from an early age. The potential role of enterprise in today's education and training systems is explored in a monograph prepared for the ILO (2002). This authors defines a set of 'enterprise skills' as, 
broadly, 'those personal dispositions, abilities and competencies related to creativity, initiative, problem solving, flexibility, adaptability, the taking and discharging of responsibility and knowing how to learn and relearn' (Wodi and Dokubo, 2005). A further main area in which tertiary education is attempting to better meet the needs of its students, with a view to their future skills requirements, is in that of teamwork. In general, our education system is based on individual work and collaboration is frowned upon and there is both student and staff resistance to its adoption. However, in the industrial setting students will normally work as part of a team with specific deadlines and cost parameters, and very often find themselves with little or no experience of such a situation prior to leaving education, which also has been noted as a failing in vocational education (Wodi and Dokubo, 2008).

\section{Methodology}

1. The ability to coordinate the information in light of the objective.

2. The ability to work to a deadline.

3. The ability to produce a group report, with equal contributions from all members.

A small survey was conducted using the FBM to help assess and develop its effectiveness in achieving these.

On completion of the feedback method, students were issued with a questionnaire to assess their experiences of the exercise. The questionnaire consisted of open-ended questions as the instructors were interested in students' commentaries in their own words. Four broad topics were chosen as the topics of enquiry: the perceived value of the exercise as a mode of learning, the challenges faced by the students through the exercise, the personal areas which the exercise had made them focus on and how they felt they had operated as part of a team. The questionnaire was issued after a 'debrief' but before marking. There are obvious biases associated with this approach, as there would be if the research were carried out after marks were issued. The response rate was 100 per cent $(\mathrm{N}=90)$, as the students were required to complete the questionnaire in class time. A factory foreman administered the questionnaire in order to minimize bias.

\section{Findings}

Due to the fact that the questions were open-ended, there were many useful, actionable comments which will help instructors to fine-tune the present exercise. The findings are split into four main sections of group work experiences, the challenges faced by the students, the personal development aspect and, lastly, the learning outcomes.

\section{The Impact on Group Work}

The findings on group work were encouraging, with the majority of respondents (92 per cent) stating that they worked well together and had initially developed an overall strategy, whereby group members were subdivided into pairs or small groups with specific tasks. 
'When asked whether the approach they used had been successful, just over 72 per cent agreed. Therefore, 72 per cent of respondents recognized that the approach they adopted had not been the best option. A variety of comments were given as to how the respondents would in retrospect - reorganize the team. The majority centred on group dynamics, including 'divide tasks', 'involve everyone', 'split group earlier' and 'decide on a leader'. Others focused on prioritization and time management - e.g. 'set objectives earlier' and 'spend more time analysing information'. All respondents felt that they had gained some insights into how they personally operated within the group scenario.

The respondents were aware of the importance of being able to work in a group and felt that replicating the group scenario in the less threatening environment provided by education also provided them with a valuable opportunity to develop this skill.

\section{Major Challenges Experienced During the Exercise}

The respondents cited a range of challenges which occurred during the exercise. The most common was 'problems with group dynamics'. This included arranging meetings and ensuring that every group member contributed equally. 'Organizing the workload within the group' was also mentioned by respondents, as was 'working under pressure'. The respondents felt that, although they recognized the need to work well in a group prior to the exercise, the exercise itself had helped crystallize how important this dynamic was to any successful outcome.

The other challenges focused on dealing with the information in the exercise from retrieving the correct feedback in the correct way, to finding time to absorb and interpret the information, to presenting the findings without time to prepare properly. This element of time management was mentioned as an issue throughout and respondents felt that this type of method helped them in developing the skill of 'thinking on their feet', which they felt conventional teaching methods could not replicate.

Only 10 per cent of the respondents stated that they found these challenges difficult. The others applied themselves to the problem at hand through effective planning, organizing and thinking logically. Sixty (60) per cent of respondents believed that the group played a large role in overcoming difficulties, with the members working closely and offering each other support when needed.

Interestingly, only 12 per cent of respondents felt that they had learned how to think tactically. Given that this is such an important skill to develop for the workplace, there is an identifiable need to develop a more tactical approach in exercises of this kind. Students tended to be more focused on looking at problems from a more strategic standpoint. This evident weakness calls into question the way in which we as academics have delivered our teaching, in that although the prime motivator may still be to get the relevant information across to students, this should be seen in context and a more holistic approach adopted. The idea of graduates being much more all-rounders than before is also supported by industry, where multi-layered management structures are less in evidence and employees are required to be multi-faceted. Participants were asked to identify what personal strengths and weaknesses the exercise had helped to highlight. 'Organizational' and 'communication' were the most common strengths mentioned (42 and 32 per cent respectively). Thereafter, other strengths included 'the ability to keep calm/work under pressure' (35 per cent), 'ability to moderate/mediate' (12 per cent), 
'ability to summarize information quickly' (46 per cent), 'negotiation and leadership' (10 per cent) and 'ability to generate ideas' ( 8 per cent). In addition to these identifiable skills, there was also the more immeasurable advantage of increased confidence in one's abilities. Respondents appreciated the chance to identify their strengths and weaknesses within a non-threatening environment.

Weaknesses revealed by the exercise included organizing and analysing large amounts of information (16 per cent), presenting on the spur of the moment ( 8 per cent) and thinking too strategically ( 32 per cent). This last point highlights the fact that not many students were aware of their inability to think tactically. In addition to the above, other comments made referred to developing assertiveness within the group scenario, being more patient and understanding towards others' needs and tasks and being less single-minded.

\section{The FBM as a Learning Tool}

When questioned on how the FBM had aided their learning, most respondents were in favour of the more active approach to learning, with 56 per cent stating that what was learned was more 'memorable' through this approach than through the lecture approach. Many felt that they had been given much greater insight into the practical problems and, although they understood the value of the theory, its application was also very important. This method had enabled them to think things through as opposed to just receiving the information as a piece of fact.

When asked specifically about what they felt they had learned, respondents stated that the greatest benefits came from the practical lessons which had been learned, which the theory cannot teach. 'Working with incomplete information' and 'cooperating with team members' were the most common responses.

Use of such learning tools in education was deemed useful, since it was felt that it went some way to replicating the industry environment, but still within the protective scenario of education. One of the main differences perceived was that they were learning how to use their combined knowledge to resolve a specific question as opposed to competing against each other individually, which is the 'traditional' teaching approach. This change in attitude was therefore the biggest challenge, but one which they found encouraging and educational from a different perspective.

\section{Outcomes}

\section{Learner's Perspective}

Learners, as documented above, perceived a number of benefits deriving from the exercise. These included a heightened appreciation of group dynamics, time management and a host of personal skills. In addition, the students professed that the approach fostered greater retention of the theory. This, however, has not been directly corroborated by the research in hand. Relating the students' comments to concerns voiced in the literature on technology education. Two of the principal benefits of the FMB have been, first, the development of the learner's ability to act on incomplete information and, secondly, increased ownership of theory - one of the objectives of enterprise learning. This exercise has gone some way to advancing the students' enterprise skills by encouraging adaptability, the taking and discharging of 
responsibility and their problem-solving capabilities. We would conclude that given the above the learners experience had been enhanced by such a method and contributed direct benefits to their development.

\section{Instructor's Perspective}

From the perspective of the instructors, the exercise provided some valuable insights into the practical development of students and their understanding of the whole subject area. The exercise allowed the instructors to test practical knowledge, as well as the students' ability to apply it, and at the same time highlighting the students' analytical skills and their ability and speed in identifying the core elements. Through the use of this method, the instructors were able to identify areas of weakness with reference to transferable skills which could therefore be addressed in other elements of the course. This insight into the range of skills being acquired by each student would not have been so evident using more conventional methods of, for example, case-study analysis.

\section{Conclusion}

The author conclude that feedback method FBM fulfils many of the activity learning' criteria discussed at the beginning of this paper. It provides a balance between the theoretical and the practical approaches in education and answers the criticism that many courses can be too focused on the theoretical elements of learning. In addition to this, the research results indicate that this form of learning is more in line with the concept of 'deep learning', since there is activity to participate on in the learning process, scope for reflection and an additional personal outcome in the form of new skills acquired or current skills being developed. Future research in this evolving area should include an analysis of the extent to which the development of such transferable skills aids a student's retention of knowledge acquired in the process.

The future curriculum is envisaged as having an increased focus on exercises such as the FBM, since the emphasis is clearly moving towards a more participative educational experience. The present government's emphasis on the need to include industry to a greater degree in the education process will, no doubt, increase both the volume and variety of exercises being used, which promote a more activity learning experience for the participating students. 


\section{References}

Aikenhead, G. S. (1997). Students Views on the Influence of Culture on Science. International Journal of Science Education, 19(4). 419 - 428.

Bassey, U. U. and Ntukidem P. J. (2001). The partial commercialization of introductory technology workshops as a sustainable strategy for financing public secondary education in Cross River State. West African Journal of Research, 8(1) March 2001.

Bassey, U. U. (2001). Correlates of Teachers' attritional tendencies in Cross River School system. West African Journal of Educational Research, 4(1) 14 - 18 April 2001

Duruamaku, Emeka Ego-Emeruem (1992). "Approaches to Developing Oral Communication for Business". Nigerian Journal of Education, Vol. 4 Nos. 1 \& 2.

Ekpenyong, L. E.(1995). Foundations of Vocational Education: New Directions and Approaches. Benin City: Supreme Ideal Publishers International Ltd.

Ezeife, A. N. (1993). "Barrier Factors in Effective Curriculum Development, Implementation and Evaluation in Nigeria" in Nworgu, B. G. (Ed). Curriculum development, implementation and evaluation. Association for Promoting Quality Education in Nigeria (APQEN).

Idialu, J. O. (1990). "An Appraisal of the Philosophy and Objectives of Vocational/Technical Education in Nigeria".

ILO (2002). International Labour Organization

Okebukola, P. A. (1992). Concept Mapping with a Cooperative Learning Flavour. The American Biology Teachers, 54(4), $218-220$.

Ukoli, F. M. A. (1981). Popularizing Science or Advertising Technology. Journal of the Science Teachers Association of Nigeria (J. STAN), 19-33.

Uyoata, U. E. (2003). Cooperative Small Group Instructional Mode and the Development of Problem Solving Ability and Attitudes in Primary Science. Unpublished ph.D. Dissertation, University of Uyo, Uyo.

Wodi, S.W. \& Dokubo, A. (2005). Challenges of Implementing School Curriculum in Nigerian Schools. Journal of curriculum organization of Nigeria (CON), VOL.12 NO 1 


\section{Macrothink}

International Journal of Learning \& Development ISSN 2164-4063 2012, Vol. 2, No. 4

Wodi, S. W. \& Dokubo, A. (2008). “Appraisal Students Industrial Work Experience Scheme (SIWES) in Five Institutions in Rivers State of Nigeria”. European Journal of Social Science, Vol. 7 Issue 3. info@ eurojournals.com www.eurojournals.com 